\title{
Structuring collaboration: Multi-user full-body interaction environments for children with Autism Spectrum Disorder
}

\author{
Ciera Crowell ${ }^{\mathrm{a}, 1}$, Joan Mora-Guiard ${ }^{\mathrm{a}}$, Narcis Pares $^{\mathrm{a}}$ \\ ${ }^{a}$ Universitat Pompeu Fabra, Carrer Roc Boronat, 138, 08018 Barcelona, Spain
}

\begin{abstract}
Background: Collaboration is an interpersonal process which builds upon social skills and mutual understanding. Due to characteristic social challenges, children with Autism Spectrum Disorders may benefit from structured collaborative virtual environments that offer adequate conditions to practice communication and social behaviors with other users. This paper provides an overview of methods to structure collaboration in multi-user technologies for autism.

Methods: Outcomes are highlighted from two full-body interaction collaborative systems which were tested to foster social behaviors in children with ASD while playing with peers. The first system, which presented an enforced collaboration paradigm, was tested with 15 users, aged from 4 to 6 , who played 4 sessions of 30 minutes each. The second system presented an encouraged collaboration paradigm tested with 10 users, aged from 10 to 14, who played 3 sessions of 15 minutes each.

Results: In both settings we observed a significant increase in social and collaborative behaviors. Controlled mechanisms may have contributed to differences in game experiences between the two paradigms, including specialized game mechanics, shared goals, narrative formation, user roles, and clear visibility of others actions.
\end{abstract}

Conclusions: Our application of this classification framework is novel in the field of interactive technologies for autism, as we identify the nature of various

${ }^{1}$ Corresponding author. E-mail: ciera.crowell@upf.edu 
methods which are used to structure collaboration, and how those affect user behavior. In formalizing these methodologies within the field of full-body interaction, we draw out knowledge that could be useful to designers of technologies for autism based on observations of related projects and our work.

Keywords: Autism Spectrum Disorders, ASD, Full-body interaction, Collaboration, Digital Technologies

\section{Highlights:}

- Structured collaborative settings can lead to positive differences in social and collaborative behaviors for children with autism, while the nature of structuring these approaches may define the user's approach to playing with others.

- Findings are reported from user studies with two embodied interactionbased systems for children with autism, highlighting differences in user behavior when user collaboration was encouraged $(n=10)$, and when collaboration was enforced $(\mathrm{n}=15)$.

- A design analysis of current and previous work reveals that collaboration may result from factors such as human mediation, specialized game mechanics, shared goals, narrative formation, user roles, free play, and clear visibility of other players' actions. 


\section{Introduction}

Collaboration occurs when two or more people coordinate related actions to achieve a common goal. Social activities such as collaboration lead to the development of cognitive skills based on active participation in the environment and learning from the tools and conversations within the social context (Rogoff. 1990). Collaboration calls for a shared understanding on a common focus of attention, which forms the grounds for communication. According to Vygotsky, the human mind is inherently social, and the development of cognitive processes is mediated by discourse and intersubjectivity (Weisner, 1987), using tools such as verbal and non-verbal language (Forman, 1992).

Collaborative scenarios can be beneficial to practice social skills for individuals with social difficulties, such as children with Autism Spectrum Disorders (ASD). Mundy et al. observed that individuals with ASD showed significant deficits in the use of joint-attention abilities, or "coordinated attention between interactive social partners with respect to objects or events in order to share an awareness" (Mundy et al., 1986). As collaboration is agreed upon through social communication, collocated mediated collaborative scenarios present an ideal approach for individuals with ASD to scaffold the learning of social behaviors such as requesting help, turn-taking, and sharing knowledge through social initiation and joint-attention.

Through collaborative settings, social behaviors are put into practice in a scenario where participants of the task have a shared goal, such as a problem solving situation. Thus, collaboration is built upon three processes: communication between group members, coordination of shared goals and responsibilities, and problem solving of given tasks (Dillenbourg, 2002).

Designing scenarios which offer children with ASD the opportunity to scaffold collaboration with a partner might be a useful way to aid in social interventions, by creating opportunities which allow for peer-to-peer communication similar to real life situations. Designers must keep in mind the level of freedom offered to players experiencing these collaborative moments, and structure 
the system's parameters accordingly. This paper offers an overview of various methods and classifications to structure collaboration in technologies for autism and their observed outcomes in our projects, which have been grounded in the principles of embodied interaction. First, we will present the background to the use and properties of digital technologies for scaffolding collaboration in children with ASD. The article will then include a review of existing digital solutions for scaffolding collaboration, categorizing projects based on their approach to collaboration. This categorization will be based on an already existing classification proposed by Benford et al. (Benford et al. 2000). Next, we will describe collaboration methods employed in the design of two full-body interactive systems which we have developed and evaluated to foster social behaviors in children with ASD. Finally, we will describe the experimental results of both projects and discuss the implications of using various methodologies of collaboration, from which design for future collaborative projects could be informed.

\section{Background}

Children with ASD show a noticeable affinity towards digital technologies, possibly due to the linear and discrete nature of computer systems (Brown \& Murray, 2001, Williams et al., 2002). This connection has strengthened the use of digital technologies as tools for social learning interventions.

\subsection{ASD and Collaborative Interventions}

ASD are a collection of neurodevelopmental disorders which present symptoms in the domains of social communication and restricted or repetitive behaviors, interests and activities (Association, 2013). Although individuals with ASD can learn to respond to the social bids of peers, they may still find it difficult to initiate social conversations. Thus, due to challenges in social interaction and communication, collaboration may be limited or compromised by their condition.

Recent research on unstructured playground dynamics suggests that children with ASD may show a higher frequency of engaging in solitary, nonsocial 
play than their typically developing counterparts (Kasari et al., 2012). Moreover, challenges in forming and maintaining relationships with peers may lead to an increase in social fragmentation in school contexts (Anderson et al. 2016). Therefore, it might be necessary to provide support during unstructured social scenarios to counter social fragmentation. A study of school-based intervention programs designed to improve social bonding found that children with ASD prefer activity-based learning with peers rather than activities with direct instruction (Bottema-Beutel et al. 2016). These findings suggest the potential of designing collaborative learning systems through activity based learning, to learn skills such as perspective taking and social communication.

Game-based interventions designed for children with ASD have proven to accelerate learning processes (Charlton et al. 2004), as children have shown increased motivation to complete the required tasks (Hoque et al., 2009). Moreover, as the efficacy of treatments for improving social functioning is mainly associated with their continuity and intensity in terms of weekly hours (Boyd et al. 2014), professionals have explored the use of digital games to complement traditional treatment methods.

\subsection{Collaborative Full-body interaction environments}

Full-body interaction can be understood as "using the movements and the actions performed in the physical space by the body of the user as mediators of the interactive experience" (Malinverni \& Pares, 2014). In the field of embodied interaction, few research projects have explored the use of full-body interaction media for the development of experiences that promote collaboration. Unlike traditional physical interfaces, this media can offer collocated experiences aimed at promoting collaboration by including the use of non-verbal body language and gestures, which have been shown to aid in thinking and in understanding others (Rambusch \& Ziemke, 2005). Also, collocating multiple users in the same physical space allows for a fluidity of awareness of other's actions (Yuill \& Rogers, 2012), creating a natural dynamic of collaboration and allowing for implicit and immediate understanding between users. 
The full-body interaction paradigm has proved successful in fostering user's engagement (Bianchi-Berthouze et al. 2007). This media seems to be effective on encouraging socialization behaviors (Lindley et al., 2008), making it suitable for the development of collaborative activities where users can practice social skills.

\subsection{Structuring digital technologies for collaboration}

The use of collaborative scenarios has been widely applied in research on digital technologies for fostering socialization between peers (Khaled et al., 2009). Much research has focused on using collaborative interactive experiences for fostering social behaviors in users with social impairments (Hendrix et al., 2009), such as ASD (Battocchi et al., 2009; Holt \& Yuill, 2014; Hourcade et al., 2012 Millen et al., 2011, Mireya Silva et al., 2015, Piper et al., 2006, Tang et al., 2015 Winoto et al., 2016). The use of technological devices specifically as mediators for collaborative learning could be motivated by their ubiquity and engaging nature, which can be a reward in itself for children with ASD (Hourcade et al. 2012).

The use of technology in collaborative scenarios allows for unique user configurations, including the physical distribution of the users when participating in the collaboration activity. Systems can be designed to allow for collocated configurations, where users are present in the same physical space, or noncollocated configurations, where users work on the same digital task but from different physical settings (e.g. accessing the same virtual environment from different desktop computers through an Internet connection). In addition to the users' physical distribution, technological settings allow for designing experiences with specific user work patterns. These patterns include working on a task individually (on their own), cooperatively (in parallel with other users), collectively (with the same contribution made by all users) or collaboratively (actively working together towards a common goal). 


\subsection{Gradients of structure}

In addition to user configurations, the use of technology also offers a high degree of customization with regard to structuring collaborative experiences. Projects can range from free play scenarios to highly sophisticated scripts for enforcing collaboration, with the intent of optimizing productivity, creativity or desired skills.

One objective of structuring collaboration is to create an even balance of user involvement, with the intention of optimizing efficiency and probability of successful outcomes. This can be both achieved through game mechanics which positively reinforce desired actions, or through human mediation by a teacher, tutor, or psychologist (Boyle \& Inmaculada Arnedillo-Sanchez, 2015). Balance may also be achieved by allowing for joint actions, where both users must complete the same action simultaneously, which may be implemented into the game mechanics to bring children together.

In the case of interactive storytelling applications, some projects may lead the user through narrative formation and offer users the choice between various plot options (Giusti et al., 2011; Cassell \& Ryokai, 2001), such as creating dialogue with characters or solving a problem, or towards a shared goal for players to complete together.

Another common method of structuring collaborative systems is to assign user roles. These roles may be symmetric or asymmetric, according to whether users perform the same or different, complementary tasks (Shah et al., 2010). These user roles can be assigned randomly, or based on criteria such as domains of expertise (Dillenbourg, 2002) or needs (Hendrix et al., 2009). By creating positive interdependence among group members through assignation of user roles, the users must cooperate in order to reap the full benefits of each user's abilities and knowledge (Hernandez-Leo et al., 2012). Similarly, limiting the resources available to users may encourage users to practice social skills in negotiating the use of existing materials.

In less structured systems, users may decide their own rules of play, forming narratives and plotlines spontaneously while playing. In a controlled experiment 
with typically developing children, Bekker, et al. compared free play versus pre-set game scenarios (Bekker et al., 2008). Children had more fun in the free play scenario and had the opportunity to practice various social skills, such as inviting others to play, while deciding their own gameplay procedures. However, free play also carries with it the potential for disruptiveness. When typically developing preschoolers were given Kidpad, a free play device for collaborative drawing, researchers observed instances of children sabotaging the drawings of their peers (Sylla, 2013). In addition, the lack of assigned user roles often leads to the emergence of a natural leader, which can result in the over-dominance of one player (Bachour et al., 2008, Bekker et al., 2008).

In full-body interactive systems, users working alongside one another may benefit from clear visibility of the other's actions, motivating engagement and collaboration in each other's activities. Along this line, Yuill and Rogers identified three mechanisms that underlie the interactions of successful multi-user collaborative interfaces: mutual awareness of other users' actions, the degree of user control over the actions within the system, and availability of background information (Yuill \& Rogers, 2012). The sources for these mechanisms can be the physical interface, the software design and the users' cultural background. According to Yuill and Rogers, by carefully arranging these properties of the system, collocated experiences can be successful in promoting collaborative behaviors. Drawbacks for structured collaboration include less individual autonomy, restricted opportunities for user expression and creativity, and frustration from being made to perform a forced activity.

\section{Related Work}

Research on scaffolding collaboration between users in the human-computer interaction domain has traditionally focused on non-collocated paradigms between computing devices, such as desktop computers or handheld devices. More recently, research has evaluated how collaboration paradigms could affect users' behavior in the Autism domain. 


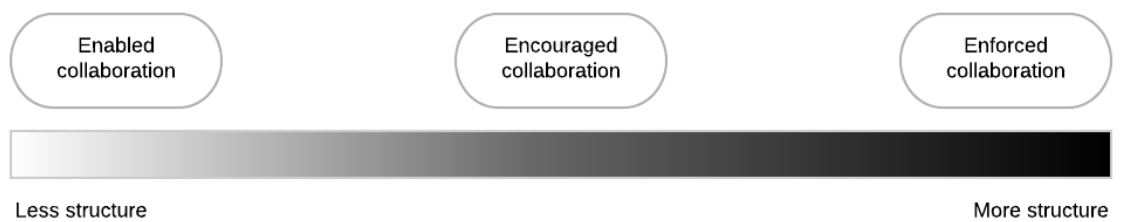

Figure 1: Collaborative systems may be classified based on the level of freedom or constraint given to user actions, resulting in more structured or less structured options for collaboration.

For Benford et al. collaboration strategies can be classified along a "collaboration continuum" (see Table1) depending on the level of freedom or constraint given to user activity (Benford et al., 2000). At one end lies "enforced collaboration", where collaboration is obligatory in order to progress in the interactive experience. At the other end lies "enabled collaboration", where users can interact independently or collaboratively, resulting in the same degree of response from the system. In between lies "encouraged collaboration", where users are not obligated to work together, but they are motivated to do so, typically by the use of positive or enhanced feedback.

\subsection{Enabled collaboration}

Enabled collaboration occurs when users are capable of collaborating on a given task, although there are no added mechanisms, scripts or rewards when users choose to collaborate. This strategy can be seen as the development of scenarios for free collaboration, where users may decide to collaborate by their own volition, without incentives from the system.

In the Telltable project, users were provided with an interactive storytelling application and were asked to photograph everyday objects which served as inspirations for narrative formation (Cao et al. 2010). In this type of free play systems, children form their own groups and draw upon their creativity to develop the game. Author observations indicated that the system empowered 
children to create their own stories, and also point out that external adult intervention was necessary for achieving proper collaborative outcomes. In 2009, Farr et al., proposed an enabled collaboration scenario through programmable tangibles that proved to reduce solitary play called Topobo (Farr et al. 2010). The use of tangibles was intended to enable "computational offloading," helping children with ASD to understand other people's actions and intentions, increasing awareness of others' behavior, and authors reported that limiting of resources promoted interaction between participants.

In 2012, Hourcade et al. developed four simple multi-touch applications for tablet devices (Hourcade et al. 2012), which included a drawing application, a musical composition device, a puzzle game, and an application to distort images which helped children with ASD explore facial expressions. All the applications lacked specific internal constraints to control collaboration, but were rather led through human mediation and session guidelines. 


\begin{tabular}{|c|c|c|c|c|c|c|c|c|c|}
\hline & 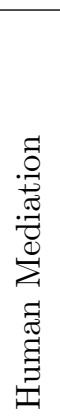 & 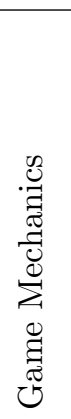 & 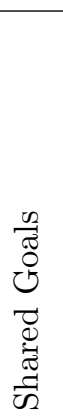 & 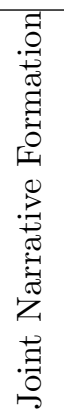 & 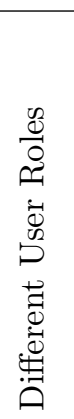 & 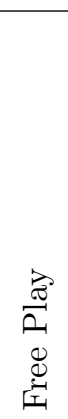 & 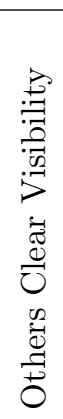 & 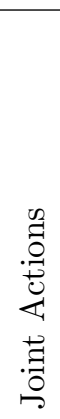 & 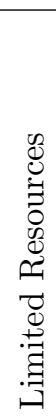 \\
\hline Telltable & $\mathrm{x}$ & & & $\mathrm{x}$ & & $\mathrm{x}$ & & & \\
\hline Topobo & & & & & & $\mathrm{x}$ & $\mathrm{x}$ & & $\mathrm{x}$ \\
\hline Hourcade et al. (2012) & $\mathrm{x}$ & & & & & & & & \\
\hline Sylla et al. (2013) & & & & $\mathrm{x}$ & & & $\mathrm{x}$ & & \\
\hline StoryTable & & & $\mathrm{x}$ & & & & & $\mathrm{x}$ & \\
\hline Collaborative Puzzle Game & & & $\mathrm{x}$ & & & & & $\mathrm{x}$ & \\
\hline Block Party CVE & & & & & & & & $\mathrm{x}$ & \\
\hline Holt and Yuill (2014) & $\mathrm{x}$ & & $\mathrm{x}$ & & & & $\mathrm{x}$ & & \\
\hline Join-in Suite & $\mathrm{x}$ & & & $\mathrm{x}$ & & & & & \\
\hline StoryMat & & & & $\mathrm{x}$ & & & & & \\
\hline Playground Architect & & & $\mathrm{x}$ & & $\mathrm{x}$ & & & & $\mathrm{x}$ \\
\hline Pico's Adventure & $\mathrm{x}$ & $\mathrm{x}$ & $\mathrm{x}$ & & $\mathrm{x}$ & & $\mathrm{x}$ & $\mathrm{x}$ & \\
\hline KidPad & & & & $\mathrm{x}$ & & $\mathrm{x}$ & & $\mathrm{x}$ & \\
\hline Klump & & & & & & $\mathrm{x}$ & & $\mathrm{x}$ & \\
\hline SIDES & & $\mathrm{x}$ & $\mathrm{x}$ & & & & & & \\
\hline Invasion of Wrong Planet & & $\mathrm{x}$ & $\mathrm{x}$ & & & & $\mathrm{x}$ & & \\
\hline Lands of Fog & & $\mathrm{x}$ & $\mathrm{x}$ & $\mathrm{x}$ & & $\mathrm{x}$ & $\mathrm{x}$ & $\mathrm{x}$ & \\
\hline
\end{tabular}

Table 1: Collaborative mechanisms implemented in related projects. The first section includes projects with enabled collaboration. The second section includes projects with enforced collaboration. The third section includes projects with encouraged collaboration.

Another enabled collaboration system was the tangible interface for collaborative storytelling designed by Cristina Sylla (Sylla, 2013), where children could 
practice narrative formation by arranging different blocks. A study with typically developing preschoolers revealed that the accessibility of tangible elements and clear visibility between actions in other children's stories made the platform successful in promoting collaboration between users.

\subsection{Enforced collaboration}

As collaborative activities become more structured, guidelines are layered which create enforced collaboration, which occurs when users are required to complete the activity by working together. The motivation behind enforced collaboration is that "by creating circumstances that inevitably demand collaboration in order to complete a desired goal, the child's brain will be required to generate and practice social skills" (Ben-Sasson et al., 2013). Research has shown that in unguided scenarios, children with ASD tend to engage in parallel play rather than collaborative play (Bauminger et al. 2008).

In 2009 Gal et al. created StoryTable, used to motivate collaboration and social behaviors in children with ASD (Gal et al. 2009). Children had to complete joint actions such as simultaneously touching a ladybug in order to choose a specific background or to listen to their taped voices. In the same year, Battochi et al. presented a similar solution, the Collaborative Puzzle Game (CPG), a tabletop system where collaboration was enforced through joint actions, as both users were required to move puzzle pieces in unison (Battocchi et al., 2009). The enforced collaboration condition was more effective than a free play condition in eliciting simultaneous coordinated activity, but also increased the challenge of completing the tasks. Both systems required fine motor skills, which may increase the difficulty of the task for people with ASD who display patterns of repetitive stereotypical movements.

Millen et al. also utilized joint actions in the COSPATIAL research project, where they developed an enforced collaboration virtual environment called Block Party CVE (Millen et al., 2011). In this project, users were required to move the same blocks in unison to achieve system goals, which reinforced communication.

Holt and Yuill presented an enforced collaboration application based on a 
separated control of a shared surface (SCoSS) where two users viewed a matrix which was used to classify objects (Holt \& Yuill, 2014). Both users had to do the same classification of objects and agree by simultaneously pushing voting buttons. The results showed that the system created more other-awareness when collaborating with a peer than with an adult partner, due to the clear visibility with regards to each other's actions.

Narrative formation can be seen in the Join-in Suite system, where users had to select between solutions to a social problem (Giusti et al. 2011). The limited interaction space to implement an enforced collaboration approach led to dominant behaviors, in some cases calling for human mediation. Another storytelling application, called StoryMat, offered users the chance to create a story revolving around specific characters (Cassell \& Ryokai, 2001).

Hendrix et al. presented the Playground Architect multi-player game to help shy children gain social confidence (Hendrix et al., 2009). Enforced collaboration was based on asymmetrical user roles, assigning shy users the role of an architect and their peers as builders who followed instructions on a large electronic game board. During trials, shy children talked as much as their peers and enjoyed leadership. Although the asymmetric responsibility seems to properly address user limitations, it does also require screening of participants while preparing the sessions.

\subsection{Encouraged collaboration}

Encouraged collaboration is the method of implementing incentives for collaboration, while allowing space for individual play. As opposed to enforced collaboration, where users must collaborate in order to complete a task, encouraged collaboration allows users to adopt their own play style depending on how

they want to engage in the game at that moment. This configuration aims to accommodate the varying dispositions towards collaboration shown by children with ASD through allowing space for children to reflect and ready themselves for socialization, and engage in collaboration when they feel comfortable to do so. In 2002 Benford et al., presented the KidStory technologies based on a Single 
Display Groupware (SDG): the KidPad, a shared drawing tool for narrative formation, and the Klump, a sculpting/modeling application to help children generate ideas in early stages of story development (Benford et al., 2000). In the KidPad application, benefits in the form of unique colors were added for when children brought their digital crayons close to other players. Working with joint actions in the Klump, when certain buttons were pressed together, children could create novel combinations of materials.

In 2006, Piper et al. presented the SIDES DiamondTouch table game, designed to help adolescents with ASD practice group work skills (Piper et al. 2006). The game was an encouraged collaboration interface, but with system mechanics to reinforce turn-taking and agreement, which prevented dominant players from taking control of the game and distributed responsibility evenly between users. Another system based on a multi-touch surface was the "Invasion of the Wrong Planet" hybrid game from Marwecki et al. (Marwecki et al. 2013), where the approach included rewarding multi-player actions more than solitary actions, and penalizing dominant behaviors. Both systems relied on interactive tabletops. This kind of small horizontal physical setting might limit other awareness, as users have to focus on a limited interactive surface losing vision of their peers with whom they are interacting.

A summary may be found in Table 1 of all reviewed articles and the different strategies adopted for motivating collaboration between users.

\section{Current Work}

\subsection{Pico's Adventure}

Pico's Adventure was a full-body interaction collaborative system developed for the European Commission research project "Motion-based adaptable playful learning experiences for children with motor and intellectual disabilities"

(M4ALL). We designed the Kinect-based videogame to help young children with ASD learn and put into practice social abilities used in collaboration such as reciprocity (i.e. turn-taking), imitation, joint-attention and cooperation. 
Practicing collaborative skills in the game was varied so children could use specific social skills in an incremental fashion over the course of four sessions. During the first session children explored to understand the extent of their control over the virtual environment while playing alone, thus avoiding a chaotic introduction to a virtual environment filled with multiple users. In the second session, children faced a problem they could not solve by themselves due to physical limitations, which required them to ask a parent for help. In order to complete the task, children were to ask parents to grab out-of-reach objects, embracing user roles to solve the problem.

During the third session, young children with ASD continued playing with their parent. Both were given a virtual laser "superpower" which extended in the direction they pointed and could be combined with the lasers of other users for extra power. The game mechanic was implemented to foster the use of pointing, a joint-attention behavior to share focus. The clear visibility of the other's superpower was meant to increase awareness of other users' actions and serve as a visual cue for helping children with ASD to practice joint-attention abilities. During the session, children employed joint actions to coordinate laser directions with their parents to free trapped spaceships, requiring them to practice socialization.

Over the three first sessions children were introduced to all the skills necessary for the fourth session, in which they played with a peer with ASD. Users were required to join their virtual lasers again, this time with the goal of obtaining presents (Figure 2). Game mechanics were configured such that both children received a unique reward with each present, which they had to open through joint selection. The rewards served as positive reinforcements for children to solve each problem, and also as a measure of progress for the children during the session. 


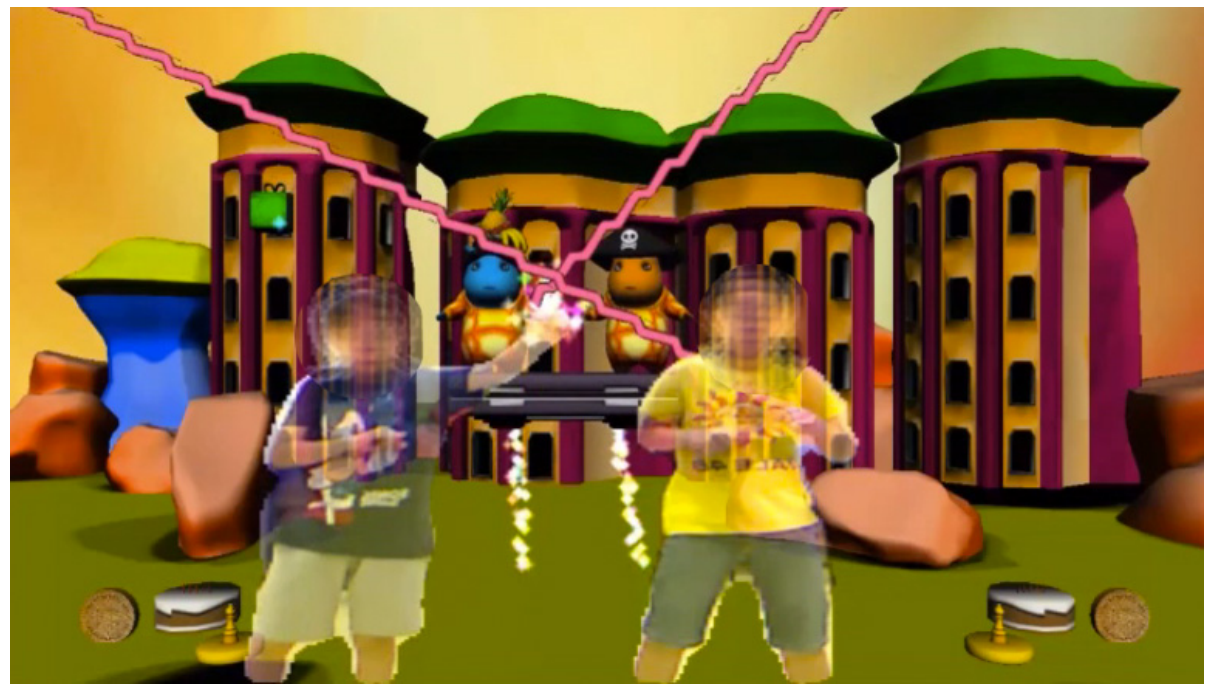

Figure 2: Two children with ASD playing the last level of Pico's Adventure. Players pointed in unison to a virtual presents to request action from the virtual agents.

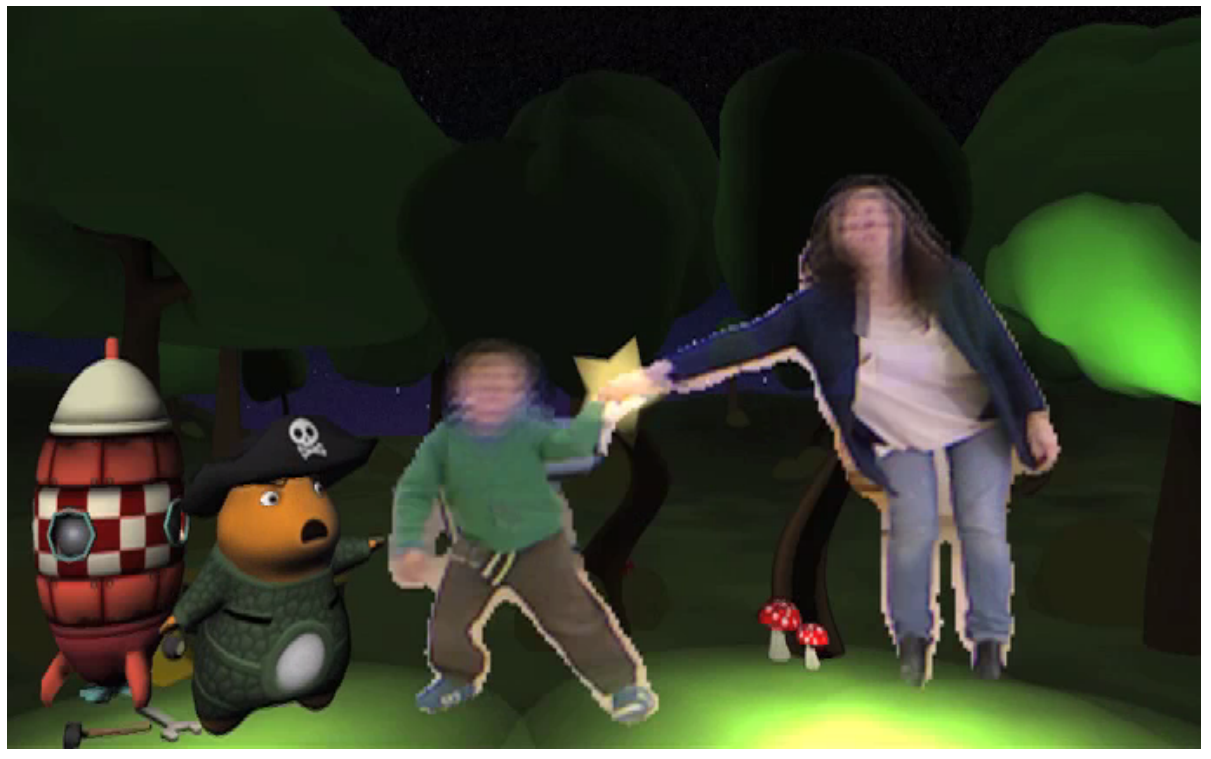

Figure 3: In Pico's Adventure, child with ASD and his mother collaborated by holding hands and collecting falling stars on their arms. 


\subsubsection{Methods}

This study was approved by the Ethics and Research Committee of Hospital Sant Joan de Du. Therefore, the study was performed in accordance with ethical standards set forth in the 2004 Declaration of Helsinki. Parents and children were given initial information about the study. Written informed consent was obtained from parents in a manner coherent with the ethical standards of the Hospital Sant Joan de Deu review boards.

\section{Participants}

A total of 15 boys with ASD were involved in the study (age: $\mathrm{M}=5,69$; SD $=0,988 ; \mathrm{IQ}: \mathrm{M}=94,40 ; \mathrm{SD}=17,79)$. The inclusion criteria were the following:

- Diagnosis for Autism Spectrum Disorder according to the Autism Diagnostic Observation Schedule (ADOS) (Lord et al. 2000) and Autism Diagnostic Interview-Revised (ADI-R) (Lord et al., 1994), applying the Diagnostic and Statistical Manual of Mental Disorders 4th Edition's (DSM-IV-TR) criteria

- Cognitive capacity above 70 as measured by the Wechsler Intelligence Scale for Children-IV (WISC-IV)

Diagnosis of ASD was confirmed by the administration of the ADI-R (Lord et al. 1994) and the ADOS Module 2 or 3 (Lord et al., 2000). All participants met cut off scores for social interaction, communication and restricted and repetitive behaviors on the ADI-R. In order to estimate IQ, the WISCIV (Wechsler, 1949) was administered to children above 6 years old. Younger participants were administered the Wechsler Preschool and Primary Scale of In-

telligence (WPPSI) (Luiselli et al., 2013) or the Kaufman Assessment Battery for Children (Loomis et al., 2010).

\section{Materials}

To evaluate the differences in social behaviors between the game and a free play condition, we recorded and video coded the sessions. The coding scheme 
(included in the appendix) observed social behaviors such as social initiations, requesting for help and responding to requests. This also took into account comments directed towards game characters, parents, the therapist, researchers, and peers.

The same video coding observational instrument was used both for quantitative behavioral observation of the child with ASD while playing with the game Pico's Adventure and also in the free play activity with toys. Two psychologists and two researchers, trained for observation of child behavior, performed the video analysis. To evaluate the reliability between the four coders an initial training was performed until reaching an acceptable inter-rater reliability score (>0.8) calculated through the Intra-class Correlation Coefficient (ICC).

\section{Procedure}

Each child played around 30 minutes during each of the four sessions. In each session children played with different partners. The order was as follows:

- In the first session children played alone. Parents, a therapist and researchers were to receive comments from the child but did not engage in gameplay.

- In the second session children started playing alone, but had to ask for help to their parents, who eventually joined in the game.

- During the third session children continued playing with their parents.

- In the last session children played with a partner with ASD, who they had not previously met.

The children also played in a control condition, which was a free play setting with different toys used by the psychologists during therapy sessions, such as cars, shopping products, puzzles or balls. Two experimental conditions were defined. In one condition, children did the free play session first and later played Pico's Adventure. In the other condition, children played in Pico's Adventure first and then did the free play session. Children were assigned to one condition or the other in random order. 


\subsubsection{Results}

The sum of the quantity of behaviors related to requests and social commentaries were used to evaluate the overall number of social initiations. Specifically, paired sample t-tests were conducted to compare the quantity of target behaviors in the Pico's Adventure condition and in the free play condition for each pair based on 4 game sessions. Only one paired samples t-test was applied for the data set of each session. The significance threshold was set at .05.

In the session where children played alone, a significant difference was reported in overall social initiations between the Pico's Adventure condition and the free play condition (see Table 2). A significant difference was also found between Pico's Adventure and free play conditions when two children with ASD were playing together (see Table 2). Nonetheless, the sum of social actions did not significantly increase during the second and third sessions of Pico's Adventure when compared to the free play setting. In both of these sessions, children played with their parents.

\begin{tabular}{|c|c|c|c|c|}
\hline$\#$ & $\begin{array}{l}\text { Pico's } \\
\text { Adventure }\end{array}$ & Free Play & Comparison & Play Condition \\
\hline 1 & $\begin{array}{l}M=9.33 ; S D \\
=9.61\end{array}$ & $\begin{array}{l}M=4.08 ; S D \\
=3.82\end{array}$ & $\begin{array}{l}t(11)=2.43 ; p \\
<.05^{*} ; \\
d=0.70\end{array}$ & Alone \\
\hline 2 & $\begin{array}{l}M=8.77 \\
S D=5.54\end{array}$ & $\begin{array}{l}M=9.69 \\
S D=4.83\end{array}$ & $\begin{array}{l}\mathrm{t}(12)=-0.46 \\
p=0.64 \\
d=-0.13\end{array}$ & With a parent \\
\hline 3 & $\begin{array}{l}M=11.15 \\
S D=7.40\end{array}$ & $\begin{array}{l}M=9.69 \\
S D=4.83\end{array}$ & $\begin{array}{l}t(12)=0.881 \\
p=0.39 \\
d=0.24\end{array}$ & With a parent \\
\hline 4 & $\begin{array}{l}M=10.93 \\
S D=5.54\end{array}$ & $\begin{array}{l}M=6.50 ; S D \\
=5.11\end{array}$ & $\begin{array}{l}t(13)=3.60 \\
p<.05^{*} \\
d=0.96\end{array}$ & $\begin{array}{l}\text { With another } \\
\text { ASD child }\end{array}$ \\
\hline
\end{tabular}

Table 2: Overall Social Initiation over 4 Sessions: Picoś Adventure vs. Free Play

When analyzing more specific social behaviors, we found a statistically significant difference on integrated requests when children were playing with their parents at the beginning of the second session. In this part of Pico's Adventure children showed a higher amount of integrated requests in Pico's Adventure ( $M$ 
$=2.33, S D=2.09)$ than in free play $(M=0.46, S D=0.51) ; t(12)=2.83, p<$

.05. Cohen's effect size value $(d=0.80)$ suggested a high practical significance.

It is also relevant to note that in the design of the second session of Pico's Adventure there was an enforced collaboration scenario that was not successful in increasing the number of social behaviors. At the end of the second session,

children were asked to grab hands with their parents to collect magic stars (see Figure 3). As children were physically in contact with their parents, they substituted social behaviors for instrumentalization, or physically placing their parent into the correct position with scarce or no communication. Thus, they skipped social communication for physical use of their partner.

\subsection{Lands of Fog}

Lands of Fog was a full-body interactive system created to foster social and collaborative behaviors in children with ASD. The game was designed through participatory design sessions to motivate children with ASD to play spontaneously in a shared setting with a partner (Mora-Guiard et al., 2016).

The game setup consisted of a 6-meter in diameter floor projected digital world, where the contents were obscured by a dense virtual fog. Users explored with the use of butterfly nets to find insects and interactive objects hidden in the digital scenario. Exploration was promoted as the fog would only part where the butterfly nets were placed (see Figure 4. The interactive elements of the game could be activated through either solo or collaborative actions, depending on the nature of the element. For example, users began the game by collecting fireflies individually, which encouraged users to use the first minutes of the game exploring the scenario on their own to become familiar with the interaction dynamics of the virtual environment. Game mechanics and goals were never introduced to users, adopting an approach similar to free play scenarios.

Later, players acquired unique creatures which could interact and merge into two novel creatures when the players used joint actions to bring their creatures close to each other. Moreover, the players could decide to explore the 


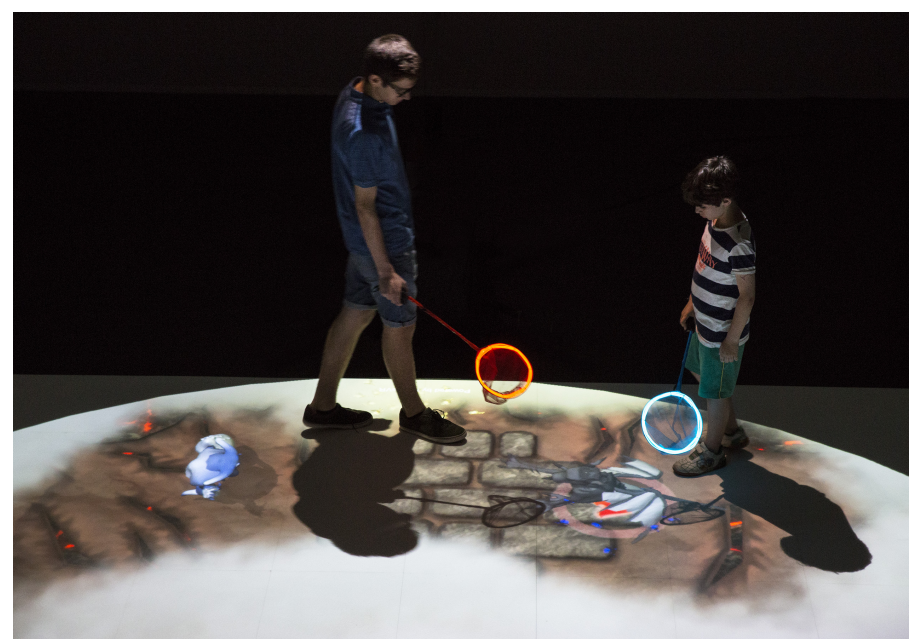

Figure 4: While playing Lands of Fog, two children bring their creatures together to manipulate an interactive object from the virtual environment. Once activated, the object will display a unique animation and both creatures will celebrate the discovery.

digital environment together and interact with hidden virtual elements, whose animations could only be activated by both creatures working together. Discovering all different elements and creatures that populated the magical world would become a shared goal between users.

The use of individual and collaborative gestures in this game was meant to construct a hierarchy of activity, with collaborative actions building upon the interaction mechanics learned during individual play. The lack of structured guidance given to players was meant to encourage sharing of information and narrative formation between the children while playing. This created a community of practice through social sharing, teaching and imitation as the partners learned the game in unison.

Moreover, revealing extra game features through the use of collaborative actions was a game mechanic meant to encourage repetition of desired actions through immediate rewards, so that the children could see the benefits of working collaboratively and open themselves to continue playing with their partner. All visual feedback, from the color of the butterfly nets, matched by their collection of fireflies, to the fog holes and creatures that would follow users' butterfly 
nets, was not only meant to help children understand their own actions but also to have a clear visibility of others' actions during play.

One guiding principle in implementing encouraged collaboration in our system was the desire to create a comfortable environment for the children with ASD if they did not immediately feel able to open up to a partner within the

exploratory format. This drew back to the goals of the game, which was to create a natural, spontaneous play experience where children with ASD could practice social initiation.

\subsubsection{Methods}

The research methodology and protocol was validated by the Ethics Committees from Universitat Pompeu Fabra in Barcelona and Goldsmiths University in London. Parents were asked to sign informed consents, previously approved also by the university ethics committee, to certify they had received sufficient information and that they agreed with their child's participation in the study. Moreover, children were informed of the activities they were going to perform and that they were free to leave if and when they desired.

\section{Participants}

In a set of controlled laboratory trials, the system was tested with a total of 10 children with ASD between the ages of 10-14. The inclusion criteria were the following:

- Diagnostic for Autism Spectrum Disorder according to ADOS (Lord et al. 2000) module 3 with a severity of 4

- Cognitive capacity above 70 as measured by the WISC-IV

The diagnosis of Autism was determined by the ADOS module 3, which is designed for young people with verbal fluency, with a minimum diagnosed severity of 4 . It was decided that verbal fluency would be essential to achieve the level of collaboration required to play the game, so the child with ASD could play without the help of a psychologist or parent. As a measure to prevent 
problems playing or comprehending the game, the children with ASD and the typically developed partners were screened for epilepsy and also were required to have an IQ of minimum 70 according to the WISC.

Materials

The video coding scheme (included in the appendix) used for the experiments was developed in unison with psychologists from Hospital Sant Joan de Du and the lead psychologist of the research project. The coding scheme was developed for observing social initiations, requests, responses, shared behaviors and gestures. It was based on the video coding scheme from Pico's Adventure, which proved to be consistent for coding these social initiation behaviors. As in the previous project, we also evaluated the reliability between the coders. An initial training was performed until three coders reached an acceptable interrater reliability (>0.8). As in the Pico's Adventure study, the reliability was again calculated through the ICC.

Moreover, each participant's playing data was recorded in log files during sessions through the use of a player tracking system. This data included information such as player position and game events.

\section{Procedure}

Each child played for a duration of 15 minutes at a time with a different partner during three experimental sessions. Experiments were arranged through randomly controlled trials by changing the playing partner for each session in Barcelona.

The procedure was as follows:

- Children were introduced to their partner for the day and had a few minutes to exchange greetings. It was assured that none of the children had a previously established friendship.

- The children were given minimal directions (such as how to hold the butterfly net for a proper tracking) so that it was their challenge to work out how to play in the experience. 
- Children would play for 15 minutes per session.

- Each session concluded with the completion of interview questionnaires regarding the child's behavior and play experience.

\subsubsection{Results}

The system was tested in an experimental setting for efficacy in fostering social and collaborative behaviors in children with ASD. A full explanation of the results of these trials may be found in (Mora-Guiard et al., 2017). For the purpose of orienting the reader, we have included key results from these experimental trails below. We applied a repeated measures ANOVA, rather than t-tests as in the previous experiment, as we wanted to observe a change between different sessions done by the same subjects. The significance threshold was set at .05 .

In the laboratory trials, children with ASD demonstrated a significant increase in the number of social initiations through the course of the 3 sessions (see Table 3). We saw a significant increase of the amount of social acts from the first session to the third session and from the second session to the third session (see Table 4). We also observed a significant increase in the number of responses made towards their typically developing partners (ANOVA: $F(2,9)=$ $8.05, p<.05)$.

\begin{tabular}{ccc}
\hline Source & $Z$ & Sig. \\
\hline Session 1-2 & -1.57 & $p=.12$ \\
Session 1-3 & -2.81 & $p<.05^{*}$ \\
Session 2-3 & -1.9 & $p=.058$ \\
\hline
\end{tabular}

Table 3: Number of Social Initiations

Children showed an increase an increase in activity levels reported by parents (ANOVA: $F(2,9)=9.56, p<.05)$ through the course of the sessions. Also, we observed a significant increase in the number of successful collaborative actions (jointly manipulating virtual elements) (ANOVA: $F(2,9)=22.9, p<.05$ ). 


\begin{tabular}{ccc}
\hline Source & $\mathrm{Z}$ & Sig. \\
\hline Session 1-1 & -1.84 & $p=.06$ \\
Session 1-3 & -2.81 & $p<.05^{*}$ \\
Session 2-3 & -2.04 & $p<.05^{*}$ \\
\hline
\end{tabular}

Table 4: Total Amount of Social Acts

\section{Discussion}

In this section we will discuss the results and observations obtained in both studies related to the use of enforced and encouraged collaboration.

\subsection{Enforced collaboration observations}

By enforcing collaboration in Pico's Adventure, children with ASD engaged in social behaviors to solve a common problem rather than doing it in a solitary fashion or through parallel play. This follows with the proposal of Ben-Sasson et al., that if users must collaborate, they will have to put into practice cognitive processes related to socialization (Ben-Sasson et al., 2013).

When designing collaborative scenarios where users are enforced to cooperate, designers have the chance to specify the different actions users will have to undergo to achieve their goal. As previously mentioned, one way of controlling collaboration is through user roles. In the second session of Pico's Adventure, children with ASD had to search for tools to help the stranded alien. Nonetheless, the control granted to the children with ASD was constrained, thus obligating them to ask their parents for help. Yuill and Rogers proposed that one mechanism for constraint in multi-user collaborative interfaces is the degree of user control over the actions within the system (Yuill \& Rogers, 2012). Our constrained control design led users to naturally cooperate with their parents, which motivated them to explicitly ask for help, therefore putting into practice social skills.

Moreover, with Pico's Adventure we could see that enforced collaboration scenarios where users have the same roles and control might allow for lowering individualistic behaviors. In the fourth session, when two children with ASD 
had to play together, we did not observe dominant behaviors. Our observations are similar to those of Battochi et al. with the Collaborative Puzzle Game (Battocchi et al., 2009), where individual decision making was reduced through enforced collaboration. We only observed dominant behaviors when children chose to play through instrumentalizing their peer. In this case, as the game mechanic was based on the physical action of holding hands and moving in unison, children found a way to do without talking. Thus, it is important to reflect on ways in which children can avoid the desired behaviors, and the effect this might have towards achieving system goals.

Nonetheless, we observed that enforced collaboration scenarios give few chances for users to explore and learn how to interact with the system. As enforced collaboration revolves around precise paths of interaction, children have little chance to creatively explore how to approach the game in their own way. This can lead to a high level of mediation from the psychologist during the experimental sessions. In previous research, some authors advocate for the intervention of psychologists, parents or caregivers during the use of collaborative interactive systems (Boyle \& Inmaculada Arnedillo-Sanchez, 2015, Hourcade et al., 2012). Although one of the advantages of digital solutions is lowering the high time demand of human therapy for children with ASD, designers must reflect upon how to leverage the autonomy of the task so that it balances human intervention with technological intuitiveness.

From literature we have seen that the use of joint actions might increase the challenge of a task (Battocchi et al. 2009, Ben-Sasson et al. 2013), which can lead to frustration by the users. In our case the potential frustration was mitigated through intervention of the psychologist and the control given to users. In Pico's Adventure, the interaction scenarios were based on digitally augmenting the capacities of the users, making the task easier because high precision was not required. The visual feedback also contributed in augmenting awareness of other users' actions, which we believed helped children with ASD to better understand and coordinate with their peer's actions. 


\subsection{Encouraged collaboration observations}

Several notable patterns of behaviors emerged as a result of the encouraged collaboration format of the game. We saw the children with ASD becoming more open to collaborating with their partner in the later stages of play, as noted by the increase in collaborative actions such as activating virtual elements together. We believe that the coordinating visual and auditory effects served as a successful reinforcement to encourage children to explore these collaborative actions. That said, we also observed an increase in individual actions, so the increase in actions could be attributed to the children's process of learning how to play the game with fluidity.

The lack of structure and guidelines let children discover the system on their own, overlaying meaning and narrative creation into their actions. Through the sharing of narrations and expectations, children had an implicit path towards collaboration and a common ground for socialization. This resulted in a dialogue of propositions between the children as they discovered the hidden features of the game, creating unique emerging narratives as they played. For example, one child saw that his creature was changing color as he caught fireflies, and commented that his creature was eating the insects. Another child said that his creature was killing the fireflies, and yet another thought that his creature was leveling up with boosts from the insects. These emerging narratives were breeding grounds for reciprocal conversation as children debated the intricacies of the game. Therefore, encouraged collaboration might be especially useful for open-ended or free play settings where the designer's goal is for children to have the opportunity to express themselves, as opposed to following a set procedure of actions.

One possible pitfall of an unstructured game was seen when a single player became dominant or individualistic during play. To prevent this, space must be left for expert mediation in the form of monitoring by a tutor or researcher. In intervention scenarios, it might also be beneficial to screen and match users with compatible personalities and levels of activity.

Instead of requiring the children to work together, we wanted to entice them 
to socialize by providing ample opportunities for engagement while playing. These opportunities came in the form of surprising and exciting elements hidden in the game that the children could share with their companion upon discovery. In this sense, just as wearing a colorful necklace can serve as a conversation starter, the game sparked initiation between players through attention catching features such as amusing creatures and object animations. For example, when creatures successfully activated a part of the scenario, they would do a lively victory dance. One inspiration for this technique came from the ECHOES virtual environment, where it was found that unexpected responses from the system were successful in sparking reactions from the children with ASD Alcorn et al. 2013).

To fully take advantage of the system's affordances in play construction, children might benefit from exploring the range of interactions in an incremental and introductory manner. For a simple object like a ball, the affordances might be readily understood: bounce, toss, roll, etc. However, in more complex systems, users might benefit from an exploratory period where they are led through the various possibilities of the system and understand how simple mechanics can be combined into more complex ones. Correspondingly, in Lands of Fog, the users first learned that butterfly nets indicate their path of movement in the game through openings in the virtual fog, and users later used this path to capture and incorporate virtual fireflies into their personal zone of activity. In this way, structured mechanics can give information to help orient players without obligating them to follow a strict procedure.

Consistent with other systems which offer the option of solitary actions, we noticed that some children became more absorbed in individual play instead of working together with their partner. In an extreme case, one boy evaded contact with his partner in order to avoid a form change in his own creature, which was implemented as a collaborative action. This interesting feedback of changing textures, which was meant to spark the curiosity of the children, worked against the goal of collaboration in that particular case because the child had become attached to his creature. This same mechanic was seen as a positive 
feature for other children who were interested in exploring the range of possible creatures in the game, thereby collaborating to change their creature with the help of their peer.

One way to dissuade isolated play might be to utilize the game space characteristics. In Lands of Fog, we designed a circular arena to create a natural flow of movement towards the center, eliminating the possibility of hiding in corners. This structure allowed for serendipitous encounters between the children as they navigated through the virtual scenario.

To respect the varying dispositions towards collaboration shown by children with ASD, encouraged collaboration takes into account the variability of attitudes and moods of players by allowing the space needed to set the pace for their own style of learning. Therefore, players are able to take the steps towards socialization when they feel comfortable to do so, which might help contribute towards a positive experience for players. Still, more research must be done to identify the emotional and biological response that arises when children with ASD interact with others during playful experiences.

\section{Implications}

In this article, we have discussed methods for structuring collaboration through digital environments, using relevant examples of our past work on collaborative systems for children with ASD. As children with ASD show tendencies towards solitary play, designers must consider ways to make collaborative play appeal to this user group. The ideal system would present these collaborative moments as positive experiences for the children with ASD so they might be more willing to try working with others in classroom or playground scenarios.

Given the information discussed in this paper, we have presented a list of preliminary observations for the efficacy of these methods in interactive systems. From the reviewed articles and the analysis of our own systems, the following guidelines might be useful when designing collocated collaborative interactive systems for children with ASD: 
- Human mediation can be implemented as a way of balancing input and unexpected behaviors from users. Care must be taken to leverage the amount of human mediation and system autonomy which is necessary. This can be based on the setting in which the interactive system is going to be used, and the designer's will with regard to increasing structure of the system.

- Testing the experience can be valuable in properly understanding when designed game mechanics are interpreted by users differently from the designer's intentions, and how these unexpected interpretations can open or jeopardize opportunities for socialization. Designers might choose to embrace the physical affordances of the system to promote mechanics such as joint actions and shared negotiation. Also, designers may choose to take into consideration the skills and limitations of the user group when designing joint actions, in order to avoid frustration.

- Having specific feedback that helps users to understand not only their own actions, but also the actions of others, will help build a common knowledge of joint activity and their consequences, also helping users understand which collaborative actions they must do together to achieve their shared goals.

- Giving users basic content which is flexible to changes may be useful to build a common understanding of the system, which can lead to greater social communication as both users form a narrative from their shared experience.

- Assigning user roles can be done by reflecting upon the capacities and limitations of each user, thus allowing for a more natural emergence of the participants' special characteristics in the experience. Also, configuring the amount of limited resources provided can increase player interdependency, leading to moments such as asking for help or negotiation of tasks. 
- Designing for a play space that embraces different game flows and learning styles may contribute to a more natural user experience. Moments of free play can be used to give users space for reflection allow interactive freedom for them to adopt individual playing styles.

It must be noted that, although studies have compared free play versus enforced collaboration settings using different systems, more research must be done in the form of controlled studies of the same system varying along the gradients of collaboration presented in this paper, in order to truly understand the behavioral tendencies, comfort level and complexities of socialization fostered by both conditions.

As discussed, measuring collaboration is typically done by assessing completion of a certain task. However, as Regh, et al. noted social interactions might not be measured best by the performance of a particular task, but should rather

be defined by the degree of the reciprocity between engaging participants (Rehg et al. 2013). Therefore, when evaluating collaboration in children with ASD, we must take into account the nature of social interactions that take place during the task and whether these contribute to a positive experience.

\section{Acknowledgments}

We would like to thank the European Commission for funding the M4ALL project (Project n 531219-LLP-1-2012-1-IT-KA3-KA3MP). We would also like to note that this publication reflects the views only of the authors, and the Commission cannot be held responsible for any use which may be made of the information contained therein. We would also like to thank La Caixa Foundation for funding the IN-AUTIS-TIC project as part of the RecerCaixa 2013 grants.

\section{References}

\section{References}

Alcorn, A. M., Pain, H., \& Good, J. (2013). Discrepancies in a virtual learning environment. In Proceedings of the 12th International Conference on Interac- 
tion Design and Children - IDC '13 (pp. 56-65). New York, New York, USA:

ACM Press. doi:10.1145/2485760.2485783.

Anderson, A., Locke, J., Kretzmann, M., \& Kasari, C. (2016). Social network analysis of children with autism spectrum disorder: Predictors of fragmentation and connectivity in elementary school classrooms. Autism, 20, 700-709. doi:10.1177/1362361315603568.

Association, A. P. (2013). Cautionary Statement for Forensic Use of DSM5. In Diagnostic and Statistical Manual of Mental Disorders, 5th Edition. Washington, DC: American Psychiatric Publishing, Inc. (5th ed.). doi:10. 1176/appi.books. 9780890425596.744053.

Bachour, K., Kaplan, F., \& Dillenbourg, P. (2008). Reflect: An Interactive Table for Regulating Face-to-Face Collaborative Learning. In Times of Convergence. Technologies Across Learning Contexts (pp. 39-48). Berlin, Heidelberg: Springer Berlin Heidelberg volume 5192 LNCS. doi:10.1007/ 978-3-540-87605-2_5.

Battocchi, A., Pianesi, F., Tomasini, D., Zancanaro, M., Esposito, G., Venuti, P., Ben Sasson, A., Gal, E., \& Weiss, P. L. (2009). Collaborative Puzzle Game. In Proceedings of the ACM International Conference on Interactive Tabletops and Surfaces - ITS '09 (p. 197). New York, New York, USA: ACM Press. doi:10.1145/1731903.1731940.

Bauminger, N., Solomon, M., Aviezer, A., Heung, K., Brown, J., \& Rogers, S. J. (2008). Friendship in High-functioning Children with Autism Spectrum Disorder: Mixed and Non-mixed Dyads. Journal of Autism and Developmental Disorders, 38, 1211-1229. doi:10.1007/s10803-007-0501-2.

Bekker, T., Sturm, J., Wesselink, R., Groenendaal, B., \& Eggen, B. (2008). Interactive play objects and the effects of open-ended play on social interaction and fun. Advances in Computer Entertainment Technology, (pp. 389-392). doi:10.1145/1501750.1501841. 
Ben-Sasson, A., Lamash, L., \& Gal, E. (2013). To enforce or not to enforce? The use of collaborative interfaces to promote social skills in children with high functioning autism spectrum disorder. Autism, 17, 608-622. doi:10. $1177 / 1362361312451526$.

Benford, S., Bederson, B., Åkesson, K., Bayon, V., Druin, A., Hansson, P., Hourcade, J., Ingram, R., Neale, H., O'Malley, C., \& Others (2000). Designing storytelling technologies to encouraging collaboration between young children. Proceedings of the SIGCHI conference on Human factors in computing systems, 2, 556-563. doi:10.1145/332040.332502.

Bianchi-Berthouze, N., Kim, W. W., \& Patel, D. (2007). Does Body Movement Engage You More in Digital Game Play? and Why? In Affective Computing and Intelligent Interaction (pp. 102-113). Berlin, Heidelberg: Springer Berlin Heidelberg. doi:10.1007/978-3-540-74889-2_10.

Bottema-Beutel, K., Mullins, T. S., Harvey, M. N., Gustafson, J. R., \& Carter, E. W. (2016). Avoiding the brick wall of awkward: Perspectives of youth with autism spectrum disorder on social-focused intervention practices. Autism, 20, 196-206. doi:10.1177/1362361315574888.

Boyd, B. A., Hume, K., McBee, M. T., Alessandri, M., Gutierrez, A., Johnson, L., Sperry, L., \& Odom, S. L. (2014). Comparative Efficacy of LEAP, TEACCH and Non-Model-Specific Special Education Programs for Preschoolers with Autism Spectrum Disorders. Journal of Autism and Developmental Disorders, 44, 366-380. doi:10.1007/s10803-013-1877-9.

Boyle, B., \& Inmaculada Arnedillo-Sanchez, A. Z. (2015). AutBlocks: Using Collaborative Learning to Develop Joint Attention Skills for Children with Autism Spectrum Disorder. In Exploring the Material Conditions of Learning: The Computer Supported Collaborative Learning (CSCL) Conference 2015. Gothenburg.

Brown, J., \& Murray, D. (2001). Strategies For Enhancing Play Skills For 
Children With Autism Spectrum Disorder. Education and Training in Mental Retardation and Developmental Disabilities, 36, 312-317.

Cao, X., Lindley, S. E., Helmes, J., \& Sellen, A. (2010). Telling the whole story. In Proceedings of the 2010 ACM conference on Computer supported cooperative work - CSCW'10 (p. 251). New York, New York, USA: ACM Press. doi:10.1145/1718918.1718967.

Cassell, J., \& Ryokai, K. (2001). Making Space for Voice: Technologies to Support Children's Fantasy and Storytelling. Personal and Ubiquitous Computing, 5, 169-190. doi:10.1007/PL00000018.

Charlton, B., Williams, R. L., \& McLaughlin, T. F. (2004). Educational Games: A Technique to Accelerate the Acquisition of Reading Skills of Children with Learning Disabilities. International Journal of Special Education, 20, 66-72.

Dillenbourg, P. (2002). Over-scripting CSCL : The risks of blending collaborative learning with instructional design. In Three worlds of CSCL: Can we support CSCL? (pp. 61-91). Heerlen, Open Universiteit Nederland. doi:10.1007/s11165-004-8795-y.

Farr, W., Yuill, N., \& Raffle, H. (2010). Social benefits of a tangible user interface for children with Autistic Spectrum Conditions. Autism, 14, 237252. doi:10.1177/1362361310363280.

Forman, E. A. (1992). Discourse, intersubjectivity, and the development of peer collaboration: A Vygotskian approach. In Children's development within social context (p. 493). Hillsdale, NJ, US: Lawrence Erlbaum Associates, Inc.

Gal, E., Bauminger, N., Goren-Bar, D., Pianesi, F., Stock, O., Zancanaro, M., \& (Tamar) Weiss, P. L. (2009). Enhancing social communication of children with high-functioning autism through a co-located interface. AI \& SOCIETY, 24, 75-84. doi:10.1007/s00146-009-0199-0.

Giusti, L., Zancanaro, M., Gal, E., \& Weiss, P. L. T. (2011). Dimensions of collaboration on a tabletop interface for children with autism spectrum 
disorder. In Proceedings of the 2011 annual conference on Human factors in computing systems - CHI '11 (p. 3295). New York, New York, USA: ACM Press. doi:10.1145/1978942.1979431.

Hendrix, K., van Herk, R., Verhaegh, J., \& Markopoulos, P. (2009). Increasing children's social competence through games, an exploratory study. In Proceedings of the 8th International Conference on Interaction Design and Children - IDC '09 (p. 182). New York, New York, USA: ACM Press. doi:10.1145/1551788.1551823.

Hernandez-Leo, D., Nieves, R., Arroyo, E., Rosales, A., Melero, J., \& Blat, J. (2012). SOS: Orchestrating collaborative activities across digital and physical spaces using wearable signaling devices. Journal of Universal Computer Science, 18, 2165-2186. doi:10.3217/jucs-018-15-2165.

Holt, S., \& Yuill, N. (2014). Facilitating Other-Awareness in Low-Functioning Children with Autism and Typically-Developing Preschoolers Using DualControl Technology. Journal of Autism and Developmental Disorders, 44, 236-248. doi:10.1007/s10803-013-1868-x.

Hoque, M. E., Lane, J. K., el Kaliouby, R., Goodwin, M., \& Picard, R. W. (2009). Exploring Speech Therapy Games with Children on the Autism Spectrum. In INTERSPEECH (pp. 1455-1458).

Hourcade, J. P., Bullock-Rest, N. E., \& Hansen, T. E. (2012). Multitouch tablet applications and activities to enhance the social skills of children with autism spectrum disorders. Personal and Ubiquitous Computing, 16, 157168. doi:10.1007/s00779-011-0383-3.

Kasari, C., Rotheram-Fuller, E., Locke, J., \& Gulsrud, A. (2012). Making the connection: randomized controlled trial of social skills at school for children with autism spectrum disorders. Journal of Child Psychology and Psychiatry, 53, 431-439. doi:10.1111/j.1469-7610.2011.02493.x. 
Khaled, R., Barr, P., Johnston, H., \& Biddle, R. (2009). Let's clean up this mess. In Proceedings of the 27th international conference extended abstracts on Human factors in computing systems - CHI EA '09 (p. 4441). New York, New York, USA: ACM Press. doi:10.1145/1520340.1520680.

Lindley, S. E., Le Couteur, J., \& Berthouze, N. L. (2008). Stirring up experience through movement in game play. In Proceeding of the twenty-sixth annual CHI conference on Human factors in computing systems - CHI '08 (p. 511). New York, New York, USA: ACM Press. doi:10.1145/1357054.1357136.

Loomis, D., Holt, R., Kaufman, J. C., \& Kaufman, A. S. (2010). Kaufman Assessment Battery for Children. In I. B. Weiner, \& W. E. Craighead (Eds.), The Corsini Encyclopedia of Psychology. Hoboken, NJ, USA: John Wiley \& Sons, Inc. doi:10.1002/9780470479216. corpsy0486.

Lord, C., Risi, S., Lambrecht, L., Cook, E. H., Leventhal, B. L., DiLavore, P. C., Pickles, A., \& Rutter, M. (2000). The autism diagnostic observation schedulegeneric: a standard measure of social and communication deficits associated with the spectrum of autism. Journal of autism and developmental disorders, $30,205-23$.

Lord, C., Rutter, M., \& Le Couteur, A. (1994). Autism Diagnostic InterviewRevised: a revised version of a diagnostic interview for caregivers of individuals with possible pervasive developmental disorders. Journal of autism and developmental disorders, 24, 659-85.

Luiselli, J., Happé, F., Hurst, H., Freeman, S., Goldstein, G., Mazefsky, C., Carter, A. S., Kaufman, A. S., Simmons, E. S., Eernisse, E. R., Tsatsanis, K., Fluit, F., Klein-Tasman, B., Feinstein, A., Kahl, A., Poyau, S., Jones, C. R. G., Volkmar, F. R., Wolf, J. M., Nadig, A., Cavanagh, P., Paul, R., \& Newman, D. B. (2013). Wechsler Preschool and Primary Scale of Intelligence. In J. S. Kreutzer, J. DeLuca, \& B. Caplan (Eds.), Encyclopedia of Autism Spectrum Disorders (pp. 3351-3360). New York, NY: Springer New York. doi:10.1007/978-1-4419-1698-3_866. 
Malinverni, L., \& Pares, N. (2014). Learning of abstract concepts through fullbody interation: A systematic review.

Marwecki, S., Rädle, R., \& Reiterer, H. (2013). Encouraging collaboration in hybrid therapy games for autistic children. In CHI '13 Extended Abstracts on Human Factors in Computing Systems on - CHI EA '13 (p. 469). New York, New York, USA: ACM Press. doi:10.1145/2468356.2468439.

Millen, L., Hawkins, T., Cobb, S., Zancanaro, M., Glover, T., Weiss, P. L., \& Gal, E. (2011). Collaborative technologies for children with autism. In Proceedings of the 10th International Conference on Interaction Design and Children - IDC '11 January 2016 (pp. 246-249). New York, New York, USA: ACM Press. doi:10.1145/1999030.1999073.

Mireya Silva, G. F., Raposo, A., \& Suplino, M. (2015). Exploring Collaboration Patterns in a Multitouch Game to Encourage Social Interaction and Collaboration Among Users with Autism Spectrum Disorder. Computer Supported Cooperative Work (CSCW), 24, 149-175. doi:10.1007/s10606-014-9214-1.

Mora-Guiard, J., Crowell, C., Pares, N., \& Heaton, P. (2016). Lands of Fog. In Proceedings of the The 15th International Conference on Interaction Design and Children - IDC '16 (pp. 262-274). New York, New York, USA: ACM Press. doi:10.1145/2930674.2930695.

Mora-Guiard, J., Crowell, C., Pares, N., \& Heaton, P. (2017). Sparking social initiation behaviors in children with Autism through full-body Interaction. International Journal of Child-Computer Interaction, 11, 62-71. doi:10.1016/j.ijcci.2016.10.006.

Mundy, P., Sigman, M., Ungerer, J., \& Sherman, T. (1986). Defining the Social Deficits of Autism: The Contribution of Non-Verbal Communication Measures. Journal of Child Psychology and Psychiatry, 27, 657-669. doi:10.1111/j.1469-7610.1986.tb00190.x. 
Piper, A. M., O’Brien, E., Morris, M. R., \& Winograd, T. (2006). SIDES. In Proceedings of the 2006 20th anniversary conference on Computer supported cooperative work - CSCW'06 (p. 1). New York, New York, USA: ACM Press. doi:10.1145/1180875.1180877.

Rambusch, J., \& Ziemke, T. (2005). The role of embodiment in situated learning. In Proceedings of the 27th Annual Conference of the Cognitive Science Society, (pp. 1803-1808). Mahwah, NJ: Lawrence Erlbaum.

Rehg, J. M., Abowd, G. D., Rozga, A., Romero, M., Clements, M. A., Sclaroff, S., Essa, I., Ousley, O. Y., Li, Y., Kim, C., Rao, H., Kim, J. C., Presti, L. L., Zhang, J., Lantsman, D., Bidwell, J., \& Ye, Z. (2013). Decoding Children's Social Behavior. In 2013 IEEE Conference on Computer Vision and Pattern Recognition (pp. 3414-3421). IEEE. doi:10.1109/CVPR.2013.438.

Rogoff, B. (1990). Apprenticeship in Thinking. Oxford University Press.

Shah, C., Pickens, J., \& Golovchinsky, G. (2010). Role-based results redistribution for collaborative information retrieval. Information Processing 8 Management, 46, 773-781. doi:10.1016/j.ipm.2009.10.002.

Sylla, C. (2013). Designing a tangible interface for collaborative storytelling to access 'embodiment' and meaning making. In Proceedings of the 12th International Conference on Interaction Design and Children - IDC '13 (p. 651). New York, New York, USA: ACM Press. doi:10.1145/2485760.2485881.

Tang, T. Y., Wang, R. Y., You, Y., Huang, L. Z., \& Chen, C. P. (2015). Supporting collaborative play via an affordable touching + singing plant for children with autism in China. In Proceedings of the 2015 ACM International Joint Conference on Pervasive and Ubiquitous Computing and Proceedings of the 2015 ACM International Symposium on Wearable Computers - UbiComp '15 (pp. 373-376). New York, New York, USA: ACM Press. doi:10.1145/ 2800835.2800913.

Wechsler, D. (1949). Wechsler Intelligence Scale for Children.. 
Weisner, T. S. (1987). Vygotsky and the Social Formation of Mind. American Anthropologist, 89, 479-480. doi:10.1525/aa.1987.89.2.02a00500. arXiv:arXiv:1011.1669v3.

Williams, C., Wright, B., Callaghan, G., \& Coughlan, B. (2002). Do Children with Autism Learn to Read more Readily by Computer Assisted Instruction or Traditional Book Methods? Autism, 6, 71-91. doi:10.1177/ 1362361302006001006 . arXiv:0803973233.

Winoto, P., Tang, T. Y., \& Guan, A. (2016). I will Help You Pass the Puzzle Piece to Your Partner if This is What You Want Me to. In Proceedings of the The 15th International Conference on Interaction Design and Children - IDC '16 (pp. 601-606). New York, New York, USA: ACM Press. doi:10.1145/ 2930674.2936012.

Yuill, N., \& Rogers, Y. (2012). Mechanisms for collaboration. ACM Transactions on Computer-Human Interaction, 19, 1-25. doi:10.1145/2147783. 2147784 . 
PICO'S ADVENTURE - DEFINITION OF THE ITEMS TO BE OBSERVED:

\section{INTERLOCUTOR:}

\begin{tabular}{|l|l|}
\hline Pico & $\begin{array}{l}\text { Recipient of social initiation is an element of the virtual } \\
\text { environment (Pico, bird, etc.), communicates with Pico only, or } \\
\text { explicitly says his name or refers to something that only Pico can } \\
\text { do }\end{array}$ \\
\hline Adult & $\begin{array}{l}\text { The recipient of the social initiation or response is the } \\
\text { accompanying adult }\end{array}$ \\
\hline Therapist & $\begin{array}{l}\text { The recipient of the social initiation or response is the therapist. In } \\
\text { the case it is not possible to clearly distinguish who the recipient } \\
\text { is, it is considered as a therapist }\end{array}$ \\
\hline Child & The recipient of the social initiation or response is the other child \\
\hline
\end{tabular}

COMMUNICATION AND SOCIAL INTERACTION:

\begin{tabular}{|c|c|}
\hline \multicolumn{2}{|c|}{ OPENINGS AND SOCIAL RESPONSES } \\
\hline Integrated demands & $\begin{array}{l}\text { Ask for help, ask for information or get the other to } \\
\text { perform an action integrating speech and look or speech and } \\
\text { gestures. }\end{array}$ \\
\hline Non-integrated demands & $\begin{array}{l}\text { Request help, ask for information or get the other to } \\
\text { perform some action without integrating look. }\end{array}$ \\
\hline social initiation & $\begin{array}{l}\text { Integration of speech and look or speech and gestures in order } \\
\text { to draw attention to something, share experience, offer } \\
\text { information and make social comments. ("Look at this", } \\
\text { "How cool!") }\end{array}$ \\
\hline $\begin{array}{l}\text { Non-integrated social } \\
\text { initiation }\end{array}$ & $\begin{array}{l}\text { Call attention to something, share an experience, offer } \\
\text { information and make social comments without integration. }\end{array}$ \\
\hline Integrated response & $\begin{array}{l}\text { Verbal responses to the interlocutor's social initiations that } \\
\text { integrate speech and look or speech and gestures. }\end{array}$ \\
\hline Non-integrated response & $\begin{array}{l}\text { response Verbal responses to the interlocutor's social initiations } \\
\text { that do not integrate speech and look or speech and gestures. }\end{array}$ \\
\hline Non-verbal response & $\begin{array}{l}\text { Responses to social initiations, requests or views of the } \\
\text { interlocutor, which do not integrate speech, look and/or } \\
\text { gestures. }\end{array}$ \\
\hline No response & No response to the requests or questions of the interlocutor. \\
\hline \multicolumn{2}{|r|}{ SHARED } \\
\hline Instrumentalization & Use of the other (eg, grasp the other's hand to do something). \\
\hline Shared Pleasure & $\begin{array}{l}\text { Indicate pleasure or enjoyment in the interaction, not in their } \\
\text { own activities. }\end{array}$ \\
\hline $\begin{array}{l}\text { Facial expressions directed } \\
\text { to others }\end{array}$ & $\begin{array}{l}\text { Facial expressions directed to another person with the } \\
\text { intention of communicating emotions. }\end{array}$ \\
\hline Look & $\begin{array}{l}\text { Directs the gaze to others in a clear, flexible, and socially } \\
\text { modulated way (to initiate, finish or regulate a social } \\
\text { interaction). }\end{array}$ \\
\hline Imitation & When you copy an action from the other without a purpose. \\
\hline Learning a specific action & $\begin{array}{l}\text { When repeating an action that the other has done with a } \\
\text { purpose in the game, the other having previously shown } \\
\text { willingness to teach the action. }\end{array}$ \\
\hline \multicolumn{2}{|r|}{ SPONTANEOUS GESTURES } \\
\hline Descriptive & Gestures to represent an object or event. \\
\hline Conventional & $\begin{array}{l}\text { Culturally established gestures, which have social significance } \\
\text { (Applauding for "Well done"). }\end{array}$ \\
\hline Instrumental & $\begin{array}{l}\text { Gestures that are used for a specific purpose (Pointing, raising } \\
\text { shoulders) }\end{array}$ \\
\hline
\end{tabular}




\begin{tabular}{|l|l|}
\hline Emphasics & $\begin{array}{l}\text { Gestures to emphasize communication (Shaking hands to } \\
\text { indicate "a lot") }\end{array}$ \\
\hline Emotional & $\begin{array}{l}\text { Use of the body to accompany emotions (surprise, pleasure, } \\
\text { disgust). Smiling is not considered. }\end{array}$ \\
\hline Greeting to the character & Gesture to greet the character. \\
\hline
\end{tabular}
HELPS:

\begin{tabular}{|l|l|}
\hline \multicolumn{2}{|c|}{ TYPE OF HELP } \\
\hline Non-verbal & $\begin{array}{l}\text { Non-verbal elp from the therapist, the adult or the child's } \\
\text { partner, such as pointing. }\end{array}$ \\
\hline Verbal & $\begin{array}{l}\text { Verbal support from the therapist, the adult or the child's } \\
\text { partner. }\end{array}$ \\
\hline Model & $\begin{array}{l}\text { Help modeled from the therapist, the adult or the child's } \\
\text { partner. In the event that it is accompanied by verbal help, it is } \\
\text { considered implicit. }\end{array}$ \\
\hline Physical & $\begin{array}{l}\text { Physical help from the therapist, the adult or the child's partner. } \\
\text { In the event that it is accompanied by verbal help, it is } \\
\text { considered implicit. }\end{array}$ \\
\hline
\end{tabular}

BEHAVIOR AND INTERESTS:

\begin{tabular}{|l|l|}
\hline \multicolumn{2}{|l|}{ REPETITIVE BEHAVIOR } \\
\hline $\begin{array}{l}\text { Repetitive actions or } \\
\text { interests }\end{array}$ & Highly repetitive behavior or interests. \\
\hline $\begin{array}{l}\text { Immediate and / or } \\
\text { delayed echolalia }\end{array}$ & $\begin{array}{l}\text { Immediate repetitions of another person's speech and/or highly } \\
\text { repetitive vocalizations. }\end{array}$ \\
\hline Rigidity & Difficulty changing context or adapting to a game change. \\
\hline $\begin{array}{l}\text { Motivational and/or verbal } \\
\text { rituals }\end{array}$ & $\begin{array}{l}\text { Activities or verbal routines that must be completed or said a } \\
\text { specific way. }\end{array}$ \\
\hline
\end{tabular}




\section{LANDS OF FOG - DEFINITION OF ITEMS TO BE OBSERVED:}

\section{INTERLOCUTOR:}

\begin{tabular}{|l|l|}
\hline P (CHARACTER) & $\begin{array}{l}\text { When the recipient of the social initiation or response is an } \\
\text { element of the virtual environment (character, fireflies ...). } \\
\text { When you receive assistance from the virtual environment (eg, } \\
\text { the character detect little activity and encouraged to follow). }\end{array}$ \\
\hline A (ADULT) & $\begin{array}{l}\text { When the recipient of the social initiation or response is the } \\
\text { accompanying adult. } \\
\text { When you receive a help from the accompanying adult. }\end{array}$ \\
\hline T (THERAPIST) & $\begin{array}{l}\text { When the recipient of the social initiation or response is the } \\
\text { therapist. } \\
\text { When you receive assistance from the therapist. }\end{array}$ \\
\hline C (PARTNER) & $\begin{array}{l}\text { When the recipient of the social initiation or response is the } \\
\text { playmate. } \\
\text { When you receive a help from another child. }\end{array}$ \\
\hline
\end{tabular}

\section{COMMUNICATION AND SOCIAL INTERACTION:}

\begin{tabular}{|c|c|}
\hline \multicolumn{2}{|c|}{ SOCIAL INITIATIONS AND RESPONSES } \\
\hline Integrated request & $\begin{array}{l}\text { Ask for help, ask for information or to make the other do an } \\
\text { action integrating speech and look or speech and gestures. }\end{array}$ \\
\hline Non-integrated requests & $\begin{array}{l}\text { Ask for help, ask for information or to make the other do an } \\
\text { action without integrating speech and look or speech and } \\
\text { gestures. }\end{array}$ \\
\hline Integrated social initiation & $\begin{array}{l}\text { Integrating speech and look or speech and gestures in order to } \\
\text { draw attention to something, share an experience, or provide } \\
\text { information and social commentary. ("Look at this", "How cool!) }\end{array}$ \\
\hline $\begin{array}{l}\text { Non-integrated social } \\
\text { initiation }\end{array}$ & $\begin{array}{l}\text { Draw attention to something, share an experience, provide } \\
\text { information and social commentary without integration. }\end{array}$ \\
\hline Integrated response & $\begin{array}{l}\text { Verbal responses to interlocutor's social initiations which } \\
\text { integrate speech and look or speech and gestures. }\end{array}$ \\
\hline Non-integrated response & $\begin{array}{l}\text { Verbal responses to interlocutor's social initiations which do not } \\
\text { integrate speech and look or speech and gestures. }\end{array}$ \\
\hline Non verbal response & $\begin{array}{l}\text { Nonverbal responses to social initiations, requests or looks from } \\
\text { the interlocutor. }\end{array}$ \\
\hline No response & No response to the requests and questions of the interlocutor. \\
\hline \multicolumn{2}{|r|}{ SHARED } \\
\hline Instrumentation & $\begin{array}{l}\text { Instrumental use of the other (eg, taking the hand of the other } \\
\text { to demonstrate will do something). }\end{array}$ \\
\hline Shared pleasure & $\begin{array}{l}\text { Indicate pleasure or enjoyment in the interaction, not in their } \\
\text { own activities. }\end{array}$ \\
\hline $\begin{array}{l}\text { Facial expressions directed } \\
\text { at otherS }\end{array}$ & $\begin{array}{l}\text { Facial expressions directed at another person with the intention } \\
\text { of communicating emotions. }\end{array}$ \\
\hline Look & $\begin{array}{l}\text { Directing gaze to others in a clear, flexible and socially } \\
\text { modulated way (to initiate, terminate or regulate social } \\
\text { interaction). }\end{array}$ \\
\hline Imitation & Copying an action of another without any purpose. \\
\hline $\begin{array}{l}\text { Learning of a specific } \\
\text { action }\end{array}$ & $\begin{array}{l}\text { When an action is repeated that another has done with a } \\
\text { purpose in the game, having shown a volition to teach that } \\
\text { specific action. }\end{array}$ \\
\hline \multicolumn{2}{|r|}{ SPONTANEOUS GESTURES } \\
\hline Descriptive & Gestures to represent an object or activity. \\
\hline Conventional & $\begin{array}{l}\text { Culturally established gestures, that have a meaning in a social } \\
\text { purpose (clap for "well done"). }\end{array}$ \\
\hline
\end{tabular}




\begin{tabular}{|l|l|}
\hline Instrumental & $\begin{array}{l}\text { Gestures that are used for achieving an objective (to point, } \\
\text { raise shoulders). }\end{array}$ \\
\hline Emphatic & $\begin{array}{l}\text { Gestures to give emphasis to communication (shake hands to } \\
\text { indicate "a lot"). }\end{array}$ \\
\hline Emotional & $\begin{array}{l}\text { use of the body to accompany emotions (surprise, pleasure, } \\
\text { disgust). Smile not considered. }\end{array}$ \\
\hline Greeting a character & Gesture of greeting a game character. \\
\hline
\end{tabular}

